\title{
MOOD DISORDER QUESTIONNAIRE-INA: PENGUJIAN KONSTRUK BERDASARKAN VALIDITAS BUTIR DENGAN METODE FACTOR ANALYSIS
}

\author{
Hosea Gunawan $^{1}$, Monty P. Satiadarma ${ }^{2}$, Rita Markus Idulfilastri ${ }^{3}$ \\ ${ }^{1}$ Psikologi Profesi, Universitas Tarumanagara Jakarta \\ Email: hosea.717181010@stu.untar.ac.id \\ ${ }^{2}$ Fakultas Psikologi, Universitas Tarumanagara Jakarta \\ Email: montys@fpsi.untar.ac.id \\ ${ }^{3}$ Fakultas Psikologi, Universitas Tarumanagara Jakarta \\ Email: ritamarkus@fpsi.untar.ac.id
}

\begin{abstract}
Mood Disorder Questionnaire-INA (MDQ-INA) is one of the most popular screening tool that has been used around the world and it has been adapted into Bahasa Indonesia. This screening tool can be very useful because it helped professional by identifying mania or hypomania symptoms on bipolar patient. The purpose of this study is to find the proof of construct validity in MDQ-Ina by using Confirmatory Factor Analysis (CFA) approach. There are 13 items that has been tested and there are 209 subjects in this study. This study is using LISREL 9.30 student version to analyze CFA based on fitness of the model, item validity with P-value > .05; positive loading factor; and t-value > 1.96. The result of this study is MDQ-INA is having 13 valid items with positif loading factor. Conclusion of this study is $M D Q-$ INA is screening tool that has a good construct validity and can be used in screening patient with bipolar and can also be use in further study or research about bipolar or screening tool.
\end{abstract}

Keywords: CFA, Mood Disorder Questionnaire, MDQ-INA, construct validity

\begin{abstract}
ABSTRAK
Mood Disorder Questionnaire-INA (MDQ-INA) merupakan salah satu alat ukur skrining gangguan bipolar yang paling sering digunakan di seluruh dunia dan telah di adaptasi ke dalam bahasa Indonesia. Alat ukur skrining ini dinilai sangat berguna karena membantu memastikan kemunculan gejala mania maupun hipomania pada pasien. Tujuan dari penelitian ini adalah untuk menguji konstruk MDQ-INA berdasarkan validitas butir menggunakan factor analysis, Confirmatory Factor Analysis (CFA). Jumlah butir tes sebanyak 13 butir, pengambilan data dilakukan kepada 209 subyek. Pengolahan data CFA menggunakan program LISREL 9.30 student, hasil pengujian berdasarkan model-fit dan validitas butir dengan $P$-Value $>.05$; factor loading positif; $t$-value $>1.96$. Hasil pengujian menunjukkan bahwa MDQ-INA memiliki 13 butir valid dengan loading factor positif. Oleh karena itu, MDQ-INA merupakan alat ukur skrining bipolar dengan validitas konstruk yang baik. MDQ-INA dapat digunakan lebih lanjut untuk melakukan skrining pada pasien maupun untuk penelitian lebih lanjut mengenai alat ukur skrining ini.
\end{abstract}

Kata Kunci: CFA, Mood Disorder Questionnaire, MDQ-INA, validitas konstruk 


\section{PENDAHULUAN}

\section{Latar Belakang}

Mood Disorder Questionnaire (MDQ) merupakan salah satu alat ukur skrining gangguan bipolar yang paling sering digunakan di seluruh dunia dan bahkan dinilai sebagai alat ukur yang sangat membantu dalam penentuan diagnosa gangguan bipolar (Hirschfeld, 2010; Yang et al., 2011). MDQ merupakan alat ukur skrining yang sangat mudah digunakan karena bersifat self-report, dicetak di selembar kertas, dan terdiri dari 13 pertanyaan dengan pilihan jawaban ya atau tidak sehingga akan memudahkan pengisian dan menghabiskan waktu yang cukup singkat (Hirschfeld, 2000; Hirschfeld, 2014). MDQ sendiri disusun oleh professor Hirschfeld dan rekan berdasarkan kriteria mania dan hipomania di DSM IV sehingga alat ukur skrining ini akan sangat membantu dalam mengidentifikasi simptom mania maupun hipomania pada pasien yang diduga memiliki gangguan bipolar (Hirschfeld, 2000). Oleh karena itu, alat ukur skrining MDQ seringkali dinilai sangat berguna dalam membantu profesional seperti psikolog maupun psikiater dalam mengidentifikasi mania maupun hipomania pada pasien dengan dugaan memiliki gangguan bipolar (Yang et al., 2011).

Mood Disorder Questionnaire (MDQ) merupakan alat ukur skrining bipolar yang telah digunakan oleh beragam pihak mulai dari setting klinis hingga peneliti, bahkan telah dikutip pada lebih dari 600 karya ilmiah serta telah diadaptasi ke berbagai bahasa seperti Finnish, Spanyol, Portugis, Chinese, dan Thai (Hirschfeld, 2010; Isometsa et al., 2003; Sanchez-moreno et al, 2008; De Sousa Gurgel, 2012; Yang et al., 2011; Waleeprakhon et al., 2014). MDQ juga telah diadaptasi ke dalam bahasa Indonesia oleh peneliti menjadi MDQ-INA. MDQ-INA diadaptasi ke dalam bahasa Indonesia melalui beberapa tahapan, yaitu: (a) word-for-word translation, proses translasi ke dalam bahasa indonesia; (b) back translate, proses translasi kembali ke bahasa semula, (c) approval of test committee, mengundang pakar untuk menilai alat ukur yang dihasilkan; dan (d) pilot study, studi awal kepada populasi target (Gunawan et al., 2020). MDQ-INA telah di uji coba terhadap 20 subyek yang telah mendapatkan diagnosis bipolar dari psikolog maupun psikiater dan juga terhadap 20 subyek yang tidak memiliki diagnosis bipolar. MDQ-INA memiliki skor reliabilitas yang tergolong baik (13 item, $\alpha=.82$ ) dan menunjukkan skor yang baik pada sensitivity $=.95$ dan specificity $=.90$ (Gunawan et al., 2020).

Pengujian validitas menggunakan pendekatan Confirmatory Factor Analysis (CFA) merupakan pengujian yang populer digunakan dalam sebagian besar penelitian untuk memberikan bukti validitas konstruk dari suatu alat pengukuran (DiStefano \& Hess, 2005; Angel et al., 2019; Idulfilastri, 2020). Pengujian validitas butir menggunakan pendekatan Confirmatory Factor Analysis (CFA) menekankan pada hubungan refleksi dari variabel teramati terhadap variabel laten. Model pengukuran yang dihasilkan akan mengkonfirmasi variabel-variabel teramati merupakan butir yang dapat merefleksikan variabel laten (Idulfilastri, 2018).

Berdasarkan hasil studi awal mengenai adaptasi MDQ ke dalam bahasa Indonesia, menunjukkan hasil yang memadai untuk digunakan di Indonesia (Gunawan et al., 2020). Dalam studi alat ukur MDQ di berbagai negara, metode validasi yang digunakan dalam penelitian MDQ hanya menekankan pada hasil sensitivity dan specificity dari alat ukur MDQ (Hirschfeld et al., 2000; De Sousa Gurgel, 2012; Yang et al., 2011; Waleeprakhon et al., 2014). Oleh karena itu, tujuan dari penelitian ini adalah untuk menyediakan bukti validitas tambahan yang berbeda dari penelitian 
sebelumnya dan hal ini akan menjadi bukti pendukung atas kelayakan penggunaan MDQ-INA melalui pengujian validitas konstruk dengan metode CFA.

\section{Rumusan Masalah}

Berdasarkan rumusan masalah yang dijabarkan di atas, maka rumusan masalah dalam penelitian ini adalah apakah model yang dihasilkan akan fit, $P$-Value $>0,05$ dan seluruh butir valid serta memiliki loading factor yang positif, t-value $>1,96$.

\section{METODE PENELITIAN}

\section{Partisipan dan Prosedur Penelitian}

Karakteristik partisipan penelitian ini adalah individu yang memiliki diagnosis gangguan bipolar serta lahir di Indonesia dan dapat memahami bahasa Indonesia. Partisipan berusia minimal 18 tahun, namun tidak dibatasi laki-laki maupun perempuan dan juga harus dapat menyelesaikan seluruh kuesioner yang diberikan. Karakteristik pada partisipan dalam control group (grup pembanding) adalah tidak memiliki diagnosis gangguan bipolar serta lahir di Indonesia dan dapat memahami bahasa Indonesia. Partisipan dalam kelompok dengan diagnosis gangguan bipolar harus mendapatkan diagnosis tersebut dari psikolog atau psikiater.

Partisipan dengan diagnosis gangguan bipolar berasal dari komunitas Bipolar Care Indonesia dan berjumlah 102 orang dan partisipan dalam kelompok pembanding berjumlah 105 orang. Teknik pengambilan sampel yang digunakan dalam penelitian ini adalah metode non-probability sampling dengan teknik purposive sampling, yaitu pengambilan sampel secara sengaja berdasarkan kriteria yang diperlukan penelitian. Jumlah sampel yang disarankan untuk studi CFA adalah lebih dari 200 partisipan (DiStefano \& Hess, 2005). Hasil sampel penelitian dari individu dengan diagnosis bipolar dikumpulkan melalui komunitas Bipolar Care Indonesia yang merupakan komunitas bipolar terbesar di Indonesia. Terbatasnya jumlah data yang terkumpul berdasarkan keputusan masing-masing dari member komunitas yang memenuhi kriteria dan ingin menjadi partisipan penelitian.

Alat ukur yang digunakan merupakan MDQ-INA (Gunawan, Satiadarma, \& Idulfilastri, 2020) yang merupakan hasil adaptasi dari alat ukur MDQ oleh Profesor Hirschfeld (Hirschfeld et al., 2000). MDQ-INA sendiri terbukti menunjukkan hasil yang baik untuk digunakan sebagai alat ukur skrining gangguan bipolar. MDQ-INA memiliki skor reliabilitas yang tergolong baik (13 item, $\alpha$ $=.82$ ) dan menunjukkan skor yang baik pada sensitivity $=.95$ dan specificity $=.90$ (Gunawan et al., 2020).

Prosedur penelitian ini dimulai dengan pengumpulan data dari MDQ-INA yang diberikan kepada partisipan penelitian. Data yang telah dikumpulkan, kemudian diolah di dalam aplikasi statistik LISREL 9.30 Student Version. Teknik pengujian validitas butir menggunakan metode Confirmatory Factor Analysis (CFA) dan berdasarkan model pengukuran SEM (Structural Equation Modelling), maka model fit bila $P$-Value $>0,05$ yang artinya data empirik sesuai dengan model yang di konsepsikan. Butir juga dinilai valid bila memiliki loading factor positif, $t$-value $>$ 1,96 . 


\section{HASIL DAN PEMBAHASAN}

Hasil pengujian konstruk menggunakan metode CFA mendapatkan hasil, yaitu terdapat 13 butir valid (model fit pada $P$-value $>.05=.084$; factor loading positif; $t$-value $>1.96$ ). Lihat Tabel 1 .

\section{Tabel 1}

Hasil Pengujian Konstruk Metode CFA

\begin{tabular}{|c|c|c|c|c|c|c|}
\hline & Butir & $\begin{array}{c}\text { Loading } \\
\text { Factor }\end{array}$ & t-value & $\begin{array}{c}\text { Standard } \\
\text { Error }\end{array}$ & Uji Butir & $\mathbf{R}^{2}(\%)$ \\
\hline \multirow{13}{*}{$\begin{array}{c}\text { P-value }=.084 ; \\
\mathrm{X}^{2}=48.19 ; \\
\text { RMSEA }=.040\end{array}$} & MDQ1_1 & .87 & 14.89 & .06 & Valid & 71.3 \\
\hline & MDQ1_2 & .74 & 11.46 & .06 & Valid & 49.6 \\
\hline & MDQ1_3 & .64 & 9.54 & .07 & Valid & 37.7 \\
\hline & MDQ1_4 & .71 & 10.74 & .07 & Valid & 45.7 \\
\hline & MDQ1_5 & .80 & 12.87 & .06 & Valid & 58.9 \\
\hline & MDQ1_6 & .83 & 13.52 & .06 & Valid & 62.4 \\
\hline & MDQ1_7 & .73 & 11.40 & .06 & Valid & 48.4 \\
\hline & MDQ1_8 & .71 & 11.03 & .06 & Valid & 47.3 \\
\hline & MDQ1_9 & .42 & 5.87 & .07 & Valid & 17.3 \\
\hline & MDQ1_10 & .74 & 10.68 & .07 & Valid & 47.0 \\
\hline & MDQ1_11 & .79 & 12.50 & .06 & Valid & 56.2 \\
\hline & MDQ1_12 & .90 & 15.34 & .06 & Valid & 74.0 \\
\hline & MDQ1_13 & .81 & 13.35 & .06 & Valid & 61.0 \\
\hline
\end{tabular}

Berdasarkan hasil analisis data, menunjukkan bahwa $P$-value $>.05=.084$ dan RMSEA $<.08=$ .04. Hal ini menunjukkan bahwa model pengukuran fit dan dapat dianalisis lebih lanjut untuk membuktikan validitas dari butir yang diuji. Bila ditinjau dari Loading Factor dari setiap butir menunjukkan bahwa Loading Factor setiap butir lebih besar dari .45 sehingga dapat disimpulkan bahwa setiap butir membangun variabel yang hendak diukur dan juga dapat dikategorikan valid. Kemudian, dapat dilihat bahwa setiap butir memiliki t-value lebih besar dari 1.96, yang menunjukkan bahwa setiap butir memiliki pengaruh masing-masing yang signifikan terhadap variabel yang diukur. Bila ditinjau dari kontribusi butir terhadap variabel maka terlihat butir MDQ1_12 (Pernahkah dalam suatu waktu Anda menjadi seperti bukan diri Anda yang biasanya dan Anda melakukan hal yang tidak biasa bagi Anda atau yang orang lain pikir berlebihan, konyol, atau berbahaya?) dan MDQ1_1 (Pernahkah dalam suatu waktu Anda menjadi seperti bukan diri Anda yang biasanya dan Anda merasa sangat gembira atau sangat bersemangat sehingga orang lain berpikir Anda bukan seperti diri Anda yang sewajarnya atau Anda sangat bersemangat sehingga mengalami masalah?) dengan $\mathrm{R}^{2}=74 \%$ dan $71.3 \%$ merupakan butir dengan kontribusi terbesar terhadap variabel yang diukur. Sedangkan butir dengan kontribusi terendah adalah butir MDQ1_3 (Pernahkah dalam suatu waktu Anda menjadi seperti bukan diri Anda yang biasanya dan Anda merasa jauh lebih percaya diri dari biasanya?) dengan $\mathrm{R}^{2}=37.7 \%$. 


\section{KESIMPULAN DAN SARAN}

\section{Kesimpulan}

Pengujian validitas konstruk pada MDQ-INA dengan metode Confirmatory Factor Analysis ini menghasilkan model fit yang mengkonfirmasi bahwa setiap butir yang ada pada alat ukur skrining bipolar MDQ-INA valid dan dapat merefleksikan dan berkontribusi bagi variabel laten yang sedang diukur. Oleh karena itu, hasil studi ini dapat menjadi pelengkap bukti validitas konstruk bagi MDQ-INA sebagai alat ukur skrining gangguan bipolar yang dapat digunakan di Indonesia.

\section{Saran}

Penelitian ini hanya menyediakan bukti validitas konstruk bagi MDQ-INA sehingga memberikan peluang bagi penelitian lebih lanjut dalam membuktikan validitas MDQ-INA melalui pendekatan lain serta studi untuk menguji reliabilitas MDQ-INA pada sampel yang lebih besar.

\section{Ucapan Terima Kasih (Acknowledgement)}

Penulis berterima kasih kepada Professor Hirschfeld karena telah memberikan nasehat mengenai hasil penelitian yang dilakukan. Kemudian, penulis juga berterima kasih kepada Ibu Vindy atas bantuannya selama di komunitas Bipolar Care Indonesia sehingga pengumpulan data partisipan dapat berjalan dengan lancar.

\section{REFERENSI}

Angel, C. M., Woldetsadik, M. A., McDaniel, J. T., Armstrong, N. J., Young, B. B., Linsner, R. K., \& Pinter, J. M. (2019). Confirmatory factor analysis of the enriched life scale among US military veterans. Frontiers in psychology, 10, 2181.

De Sousa Gurgel, W., Rebouças, D. B., Negreiros De Matos, K. J., Carneiro, A. H. S., \& Gomes De Matos E Souza, F. (2012). Brazilian Portuguese validation of Mood Disorder Questionnaire. Comprehensive Psychiatry, 53(3), 308-312. https://doi.org/10.1016/j.comppsych.2011.04.059

DiStefano, C., \& Hess, B. (2005). Using confirmatory factor analysis for construct validation: An empirical review. Journal of Psychoeducational Assessment, 23(3), 225-241.

Gunawan, H., Satiadarma, M. P., \& Idulfilastri, R. M. (2020). Mood disorder questionnaire-ina: Studi adaptasi alat ukur skrining bipolar. Jurnal Muara Ilmu Sosial, Humaniora, dan Seni, 4(1), 196-203. https://doi.org/10.24912/jmishumsen.v4i1.7442.2020

Hirschfeld, R. M. A. (2010). Mood disorder questionnaire: It's impact on the field. Depression and Anxiety, 27(7), 627-630. https://doi.org/10.1002/da.20697

Hirschfeld, R. M. A. (2014). Differential diagnosis of bipolar disorder and major depressive disorder. Journal of Affective Disorders, 169(1), 12-16.

Hirschfeld, R. M. A., Williams, J. B. W., Spitzer, R. L., Calabrese, J. R., Flynn, L., Keck, J., Lewis, L., McElroy, S. L., Post, R. M., Rapport, D. J., Russell, J. M., Sachs, G. S., \& Zajecka, J. (2000). Development and validation of a screening instrument for bipolar spectrum disorder: The mood disorder questionnaire. American Journal of Psychiatry, 157(11), 1873-1875. https://doi.org/10.1176/appi.ajp.157.11.1873 
Idulfilastri, R. M. (2018). Pengujian konstruk tes potensi manajerial berdasarkan validitas butir dengan metode factor analysis. Jurnal Muara Ilmu Sosial, Humaniora, dan Seni, 2(1), 189197. http://dx.doi.org/10.24912/jmishumsen.v2i1.1597

Isometsä, E., Suominen, K., Mantere, O., Valtonen, H., Leppämäki, S., Pippingsköld, M., \& Arvilommi, P. (2003). The Mood Disorder Questionnaire improves recognition of bipolar disorder in psychiatric care. BMC Psychiatry, 3, 1-4. https://doi.org/10.1186/1471-244X3-8

Sanchez-moreno, J., Villagran, J. M., Gutierrez, J. R., Camacho, M., Ocio, S., Palao, D., Querejeta, I., Gascon, J., Sanchez, G., \& Vieta, E. (2008). Adaptation and validation of the Spanish version of the Mood Disorder Questionnaire for the detection of bipolar disorder. Bipolar Disorders, 10(3), 400-412. https://doi.org/10.1111/j.1399-5618.2007.00571.x

Waleeprakhon, P., Ittasakul, P., Lotrakul, M., Wisajun, P., Jullagate, S., \& Ketter, T. A. (2014). Development and validation of a screening instrument for bipolar spectrum disorder: The Mood Disorder Questionnaire Thai version. Neuropsychiatric Disease and Treatment, 10, 1497-1502. https://doi.org/10.2147/NDT.S67842

Yang, H. chen, Yuan, C. mei, Liu, T. bang, Li, L. jiang, Peng, H. jun, Rong, H., Liao, C. ping, Shen, Q. jie, \& Fang, Y. ru. (2011). Validity of the Chinese version Mood Disorder Questionnaire (MDQ) and the optimal cutoff screening bipolar disorders. Psychiatry Research, 189(3), 446-450. https://doi.org/10.1016/j.psychres.2011.02.007 